\title{
Genomic databanks and targeted assays help characterise domestic mosquito incursions
}

\author{
Thomas L. Schmidt ${ }^{1}$, Nancy Endersby-Harshman ${ }^{1}$, Nina Kurucz ${ }^{2}$, William Pettit ${ }^{2}$, Vicki L \\ Krause $^{3}$, Gerhard Ehlers ${ }^{4}$, Odwell Muzari ${ }^{4}$, Bart J Currie ${ }^{5,6}$, Ary A Hoffmann ${ }^{1}$ \\ ${ }^{1}$ Bio21 Institute, School of BioSciences, University of Melbourne, Parkville, VIC, Australia \\ 2 Medical Entomology, Northern Territory Centre for Disease Control, Northern Territory Department of \\ Health, Darwin, NT, Australia \\ ${ }^{3}$ Northern Territory Centre for Disease Control, Northern Territory Department of Health, Darwin, NT, \\ Australia \\ ${ }^{4}$ Medical Entomology, Tropical Public Health Services Cairns, Cairns and Hinterland Hospital \& Health \\ Services, Cairns, QLD, Australia \\ ${ }^{5}$ Global and Tropical Health Division, Menzies School of Health Research, Charles Darwin University, \\ Darwin, NT, Australia \\ 6 Infectious Diseases Department and Northern Territory Medical Program, Royal Darwin Hospital, Darwin, \\ NT, Australia
}

\begin{abstract}
Biosecurity strategies aiming to restrict the spread of invasive pests can benefit from knowing where new incursions have come from. This knowledge can be acquired using genomic databanks, where genetic variation in incursion samples is compared against variation in reference samples. Here, we use genomic databanks to investigate domestic incursions of two mosquito species in Australia. We used a deep learning method to trace a 2021 invasion of Aedes aegypti in Tennant Creek, Northern Territory, to Townsville, Queensland, and to trace Ae. albopictus incursions between several invaded and uninvaded islands in the Torres Strait. We observed high precision of tracing despite 30-70 generations separating incursions and source samples. Targeted assays also improved precision, in this case by comparing Wolbachia infection data to mitochondrial DNA variation in Ae. aegypti. For Ae. albopictus, incursions detected in 2021 were traced to different islands than incursions detected in 2019. Patterns of relatedness and inbreeding indicated that Tennant Creek was likely invaded by Ae. aegypti from one family, whereas Torres Strait incursions involved distinct kinship groups. Our results highlight the value of repeated tracing with genomic databanks that remain informative over years, and demonstrate how additional targeted assays (e.g. Wolbachia) can improve inferences.
\end{abstract}

Keywords: $\quad$ genomic databanks; incursions; deep learning; biosecurity; Aedes mosquito; Wolbachia 


\section{Introduction}

Invasions of exotic pests confer a global economic burden of over $\$ 200 \mathrm{~B}$ annually (1). These costs have risen in recent decades and are expected to rise further as invasions continue to increase in frequency worldwide (2). For invertebrates, most invasions establish via accidental transportation on ships, planes, or land vehicles, and are typically hard to eradicate with insecticides due to resistance that is either present on arrival or evolved shortly afterward (3). Border biosecurity operations have demonstrated success at restricting the spread of pests $(4,5)$, however, resource limitations restrict the number of inspections on arriving vessels and the number of border sections that can be effectively monitored.

Biosecurity operations can be greatly assisted by knowledge of incursion pathways, as this allows for more frequent inspection of goods and conveyances from likely source locations (6) and regular inspection of known entry points $(7,8)$. While pathways may be easily inferred if incursions are detected on their vessel of entry, incursions that are detected later pose a greater challenge. Recent work using genomic databanks to trace incursions or recently established invasions indicates that these methods can reliably infer the most likely origin out of a set of reference populations (9-16), and are particularly useful for tracing samples collected beyond border biosecurity. These methods compare genome-wide genetic variation in the incursion or invasion of interest against variation across reference samples, allowing the invasion to be linked to a population or a set of related populations of origin depending on the quality of the database.

This study presents genomic tracing results for two mosquito species, the dengue mosquito Aedes aegypti and the tiger mosquito Ae. albopictus. Previous work on tracing these mosquitoes in Australia has focused on determining the country of origin of incursion samples collected at airports and seaports $(13,15)$. In addition, some tracing of $A e$. albopictus has also been completed within the Torres Strait Islands, Queensland, as part of a study considering population structure across this region (14).

Here we focus on new in-country detections within Australia away from entry ports where invasive samples of unknown provenance have been detected. For Ae. aegypti, we trace an invasion of Tennant Creek, Northern Territory, that was detected in early 2021. For Ae. albopictus, we trace a set of new incursions detected in the Torres Strait on islands where this species has been successfully eliminated (4) and where previous tracing of 2019 incursions indicated a nearby island, Keriri, as a source of incursions (14). For the Ae. aegypti invasion, we show how precise tracing can be achieved despite reference data being collected $\geq 7$ years previously. We also use targeted assays for insecticide resistance and a Wolbachia infection to improve precision of tracing, which follow releases to establish Wolbachia in north eastern Australia over the last decade (17-19). For Ae. albopictus, we trace the 2021 incursions to a different set of islands than the source of the 2018 incursions, and we show that precision of tracing has not decreased despite frequent dispersal among 
the invaded islands $(14,20)$. Finally, by comparing genetic relatedness among samples in both species, we find evidence that the Ae. aegypti invasion was likely sourced from a single geographical location and potentially from a single family, while the Ae. albopictus incursions were from different family groups.

\section{Materials and Methods}

\section{Mosquito sample collection}

\section{Aedes aegypti invasion of Tennant Creek, NT, Australia}

Aedes aegypti was detected in Tennant Creek during routine surveillance between $22^{\text {nd }}$ $26^{\text {th }}$ February 2021. Four adult mosquitoes from this new invasion (three females, one male) were collected from a single property at $26^{\text {th }}$ February. Follow-up sampling between $9^{\text {th }}$ $11^{\text {th }}$ March located an additional five adults (three females, two males) and nine immatures at four properties within $\sim 80 \mathrm{~m}$ of the original detection.

To trace the source of this invasion, we built a genomic databank from 80 Ae. aegypti sampled from 11 locations across its Australian distribution in Queensland, from the northern islands of the Torres Strait $\left(9.3^{\circ} \mathrm{S}\right)$ to Goomeri in southeast Queensland $\left(26.2^{\circ} \mathrm{S}\right)$ (Fig 1a). These were sampled between 2009 and 2017. We also included previouslygenerated sequence data from Cairns (21) and Townsville (22), sampled in 2015 and 2014 respectively. The Cairns sample included some individuals infected with Wolbachia from earlier releases (19) while the Townsville sample was taken before Wolbachia releases in this area (17).

\section{Aedes albopictus incursions in the Torres Strait Islands, QLD, Australia}

Aedes albopictus incursions were detected during routine surveillance on two islands in the Torres Strait where the species has been successfully eliminated (4). Surveillance conducted in January and February 2021 detected four adult individuals from Thursday Island and three from Horn Island (Fig 1b). On each island, the incursions were not restricted to a single location. On Horn Island the incursive mosquitoes were collected from two locations $\sim 600 \mathrm{~m}$ apart (Figure S1), while on Thursday Island the incursions were spread across four locations $\sim 1 \mathrm{~km}$ apart (Figure S2). 

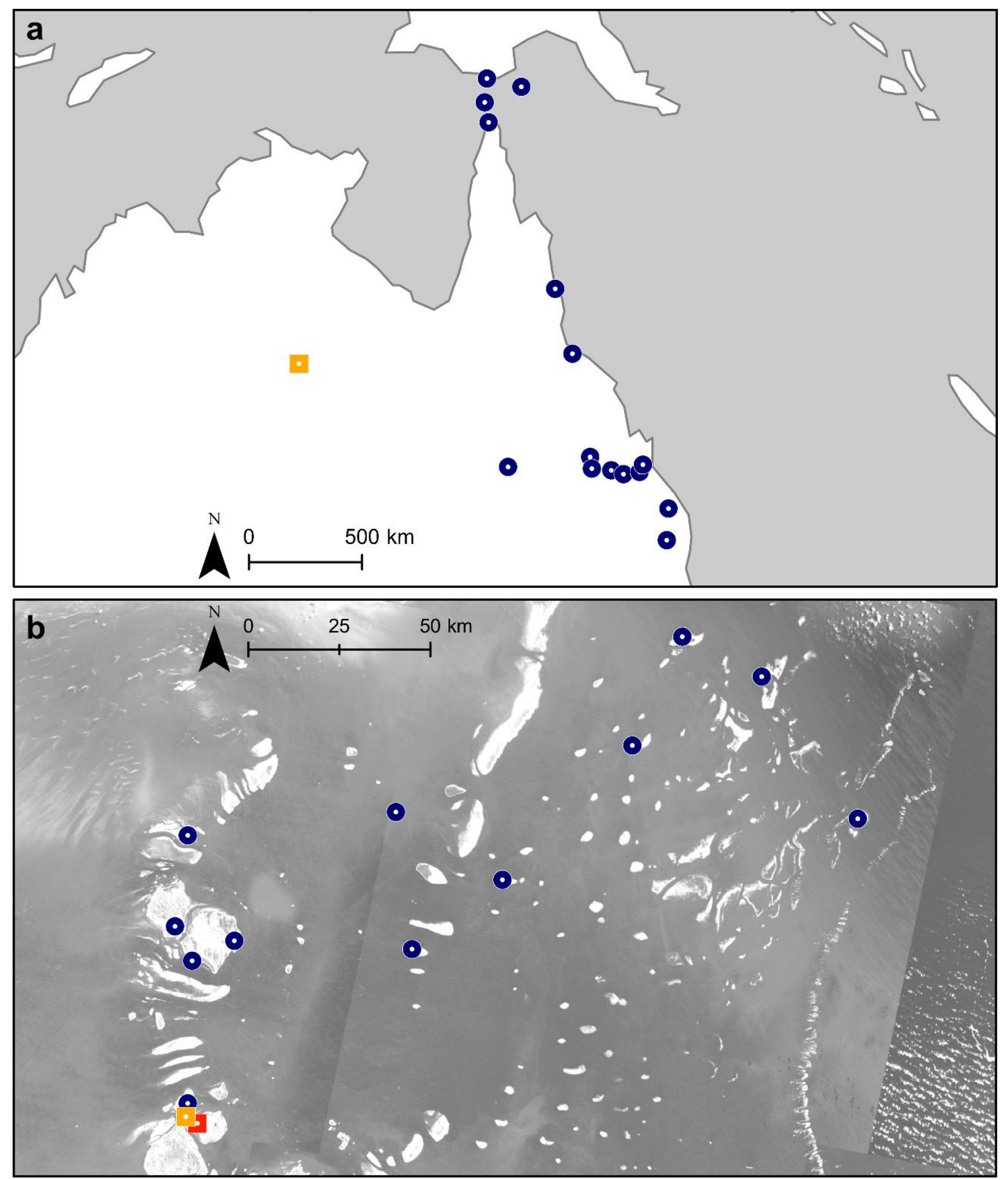

Figure 1. Locations of Ae. aegypti (a) and Ae. albopictus (b) samples. Blue circles show locations of reference samples. In (a), the orange square indicates Tennant Creek. In (b), the orange square indicates Thursday Island and the red square indicates Horn Island.

To trace the source of this invasion, we used a genomic databank containing previously generated sequence data of 240 Ae. albopictus from 12 Torres Strait Island communities 
across 11 islands, collected in 2017 (14) (Fig 1b). Before tracing among Torres Strait Island locations, we checked to ensure that the sample was not from either Papua New Guinea or Indonesia using the same methods as for other tracing and found that they all had a Torres Strait Island origin.

\section{DNA sequencing and bioinformatic processing}

Genomic DNA was extracted from the 98 Ae. aegypti and 7 Ae. albopictus using Qiagen DNeasy ${ }^{\circledR}$ Blood \& Tissue Kits (Qiagen, Hilden, Germany). Extracted DNA was used to build double digest restriction-site associated DNA (ddRAD; (23)) sequencing libraries following the protocol of Rašić, Filipović, Weeks, \& Hoffmann (2014). A technical replicate was produced of one of the Torres Strait Island incursion samples from Thursday Island, TI-1, which was replicated through the entire protocol after DNA extraction. Libraries were individually barcoded, then sequenced on a HiSeq 4000 using 150 bp chemistry.

New and old sequence data were combined for each species, and run through the same bioinformatic pipeline. We used the Stacks v2.54 (25) program process_radtags to demultiplex sequences, trim them to $140 \mathrm{bp}$ and remove sequences with Phred scores below 20. As the Cairns and Townsville libraries were produced using 100 bp chemistry, we trimmed these to $80 \mathrm{bp}$. Sequences were aligned to the nuclear genome assembly for $A e$. aegypti, AaegL5 (26), and the linkage-based assembly for Ae. albopictus, AalbF3 (27). Alignment was in Bowtie2 v2.3.4.3 (28) using "-very-sensitive" settings. Sequences were built into catalogs for each species using the Stacks program ref_map.

The Stacks program "populations" was used to export VCF files containing SNP genotypes for all individuals in each catalog, filtering to retain SNPs called in at least $75 \%$ of individuals from each population. VCFtools v0.1.16 (29) was used to further filter SNPs to retain those scored in $95 \%$ of all individuals, with a minor allele count $\geq 3$ (30), and at least $25 \mathrm{kbp}$ from other SNPs. Two of the 18 Tennant Creek Ae. aegypti had too high missing data for genomic analysis and were omitted.

\section{Incursion tracing}

\section{i) Genome-wide genetic variation}

We used Locator (31) to infer the origin of the 16 invasive Ae. aegypti and the 8 incursive Ae. albopictus (including the technical replicate). Locator is a deep learning method that uses individual genotypes of known geographical location (i.e. the reference individuals) to predict the locations of a set of individuals of unknown location (i.e. the incursive mosquitoes). For each incursive mosquito, we set Locator to provide a point estimate of its origin and 1,000 bootstrap subsamples to indicate confidence around these estimates. 
The Tennant Creek Ae. aegypti were assessed for infection of wMel Wolbachia, which are present at high frequency in Ae. aegypti populations in Cairns, Townsville, and several other locations in northern Queensland, but not in central Queensland populations. Wolbachia infection was assessed using a high-throughput PCR assay (32) which was run twice on all 18 samples.

In the case of uninfected samples, we also considered the possibility that the wMel infection was initially present but then lost from the invasive population due to the vulnerability of this Wolbachia strain to high temperatures (33) that are common in Tennant Creek. As Wolbachia is coinherited with mtDNA through the maternal line (34), wMel-infected individuals will all have inherited the same mtDNA haplotype from the same common ancestor within the past 10 years. This mtDNA haplotype will be retained even if Wolbachia has been lost (35), and its presence would be revealed by high genetic similarity in mtDNA between the Tennant Creek Ae. aegypti and samples infected with wMel.

To test this hypothesis, we looked at mtDNA variation among our Ae. aegypti samples alongside variation from $38 \mathrm{wMel}$-infected (Wol+) and 87 uninfected wildtype (Wol-) individuals from Cairns, sampled in 2015 (21). We aligned demultiplexed sequences to the Ae. aegypti mtDNA genome assembly (36) and called mtDNA SNPs using Stacks. We used VCFtools to output mtDNA genotypes for all individuals with minimum depth of 5, omitting SNPs with any heterozygous genotypes which could represent NUMTs (37).

\section{iii) Pyrethroid resistance mutations}

The Tennant Creek Ae. aegypti were assessed for three pyrethroid resistance mutations common to Ae. aegypti across the Indo-Pacific (38), but not within Australia (39). For each individual, we ran three replicates of the Custom TaqMan ${ }^{\circledR}$ SNP Genotyping Assays (Life Technologies Corporation, Carlsbad, CA, USA) described in Endersby-Harshman et al. (2020), using on LightCycler II 480 (Roche, Basel, Switzerland) real time PCR machine in a 384-well format.

\section{Genetic relatedness and inbreeding in the incursions}

We investigated patterns of genetic relatedness ( $k$ ) among pairs of individuals (dyads) in the Tennant Creek and Torres Strait incursions, and calculated Wright's inbreeding coefficient $(F)$ for every individual. The patterns can help indicate whether the samples at either location had likely arrived as part of a single incursion or several distinct incursions. For instance, if several incursive individuals had arrived via the same incursion on the same vessel, dyads of these individuals should have higher $k$ scores than other dyads in the 
sample, as they will either be from the same family or have high genetic similarity due to their shared geographical origin. Alternatively, if the invasion was sourced from a single family and related individuals have subsequently mated together, we would expect to see higher $F$ scores than in other populations. If neither of these patterns are present, it would suggest that invasive samples represent different incursions.

We used Loiselle's k (40) to estimate genetic relatedness, calculated in SPAGeDi (41). Loiselle's $k$ describes correlations in the frequencies of homologous alleles, summarised across the genome (40). We used this estimator as it makes no assumptions regarding $F$ and is suitable for markers with low polymorphism (42). We calculated $F$ in VCFtools (29). As estimators of individual-level variation can be biased by uneven sample size and missing data (43), we subsampled and refiltered each databank before calculating F. For Ae. aegypti, we used the Tennant Creek ( $n=16)$, Townsville $(n=16)$ and Cairns $(n=15)$ samples. For Ae. albopictus, we used $n=7$ samples from each reference population and the $n=7$ incursion samples. We filtered to omit all sites with any missing genotypes (--max-missing 1 ) and to keep only sites with mean depth $\geq 20$ (--min-meanDP 20).

\section{Results}

\section{Incursion tracing}

\section{Aedes aegypti invasion of Tennant Creek, NT, Australia}

Genomic tracing with Locator was run sequentially on different subsets of samples. An initial run with all 112 reference samples and 11866 SNPs indicated all 16 samples had a likely origin between Cairns ( $16.9^{\circ} \mathrm{S}$ ) and Rockhampton (23.4 $\mathrm{S}$ ) (Fig S3). Rerunning Locator with reference samples outside this range omitted and 11495 SNPs indicated a likely origin of Townsville (Fig 2).

We checked whether this assignment to origin was biased by Townsville's geographically central location by rerunning Locator using either Townsville and Cairns only (Fig S4) or Townsville and the southern samples only (Fig S5). In each case, incursives were still placed around Townsville, but Townsville and Cairns were slightly harder to differentiate.

Assays for wMel Wolbachia indicated none of the Tennant Creek samples were infected with $w$ Mel. Analysis of 116 mitochondrial SNPs showed that pairwise $F_{\text {ST }}$ between Tennant Creek and Townsville was lower $\left(F_{\mathrm{ST}}=0.26\right)$ than between Tennant Creek and either of the Cairns samples (both $F_{S T}=0.85$ ) (Table 1). This indicates that no wMel infection was ever present in the Tennant Creek samples or their maternal ancestors. In the pyrethroid resistance assays none of the three resistance alleles were present in the Tennant Creek samples. 


\section{Aedes albopictus incursions in the Torres Strait Islands, QLD, Australia}

Locator, run using 2403 filtered SNPs, indicated several of the incursives had an origin in the Maluilgal (Western) island group (Fig 3). These included the TI-1 sample and its technical replicate TI-1r, which were both traced specifically to Moa Island with very low variation among the bootstrap samples. $\mathrm{TI}-3$ and $\mathrm{HI}-3$ were also linked to the Maluilgal group, though they could not be linked to a specific island, and TI-4 was linked to a lesser extent to this group. The remaining incursives could not be placed with any specificity. Unlike a previous sample from 2019, none of the 2021 incursives were clearly linked to Keriri in the Kaiwalagal (Inner) island group.
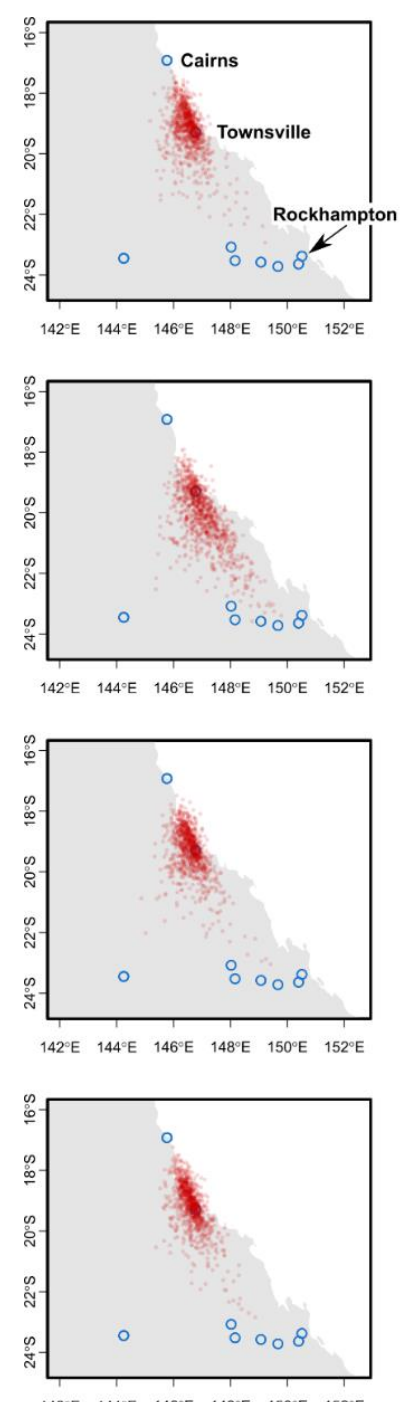

$142^{\circ} \mathrm{E} \quad 144^{\circ} \mathrm{E} \quad 146^{\circ} \mathrm{E} \quad 148^{\circ} \mathrm{E} \quad 150^{\circ} \mathrm{E} \quad 152^{\circ} \mathrm{E}$

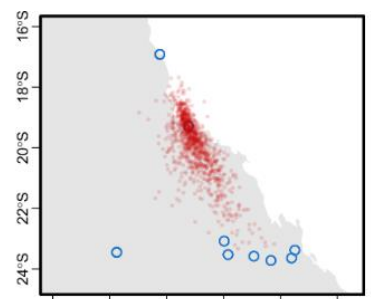

$142^{\circ} \mathrm{E} \quad 144^{\circ} \mathrm{E} \quad 146^{\circ} \mathrm{E} \quad 148^{\circ} \mathrm{E} \quad 150^{\circ} \mathrm{E} \quad 152^{\circ} \mathrm{E}$
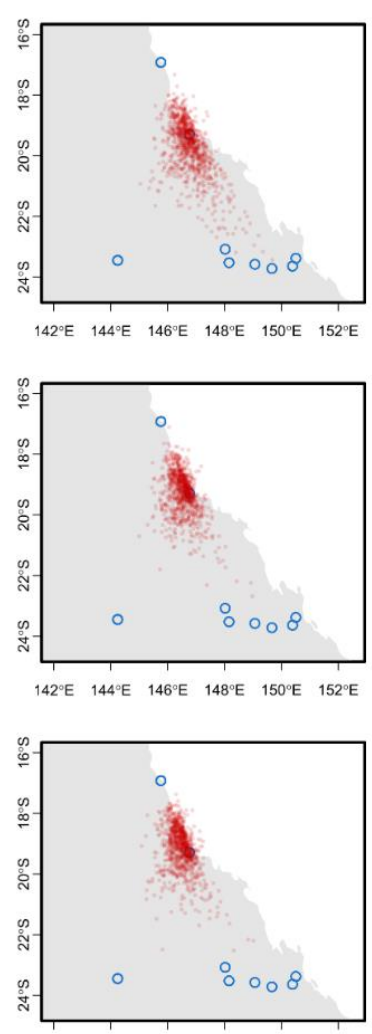

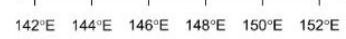

Training Locations
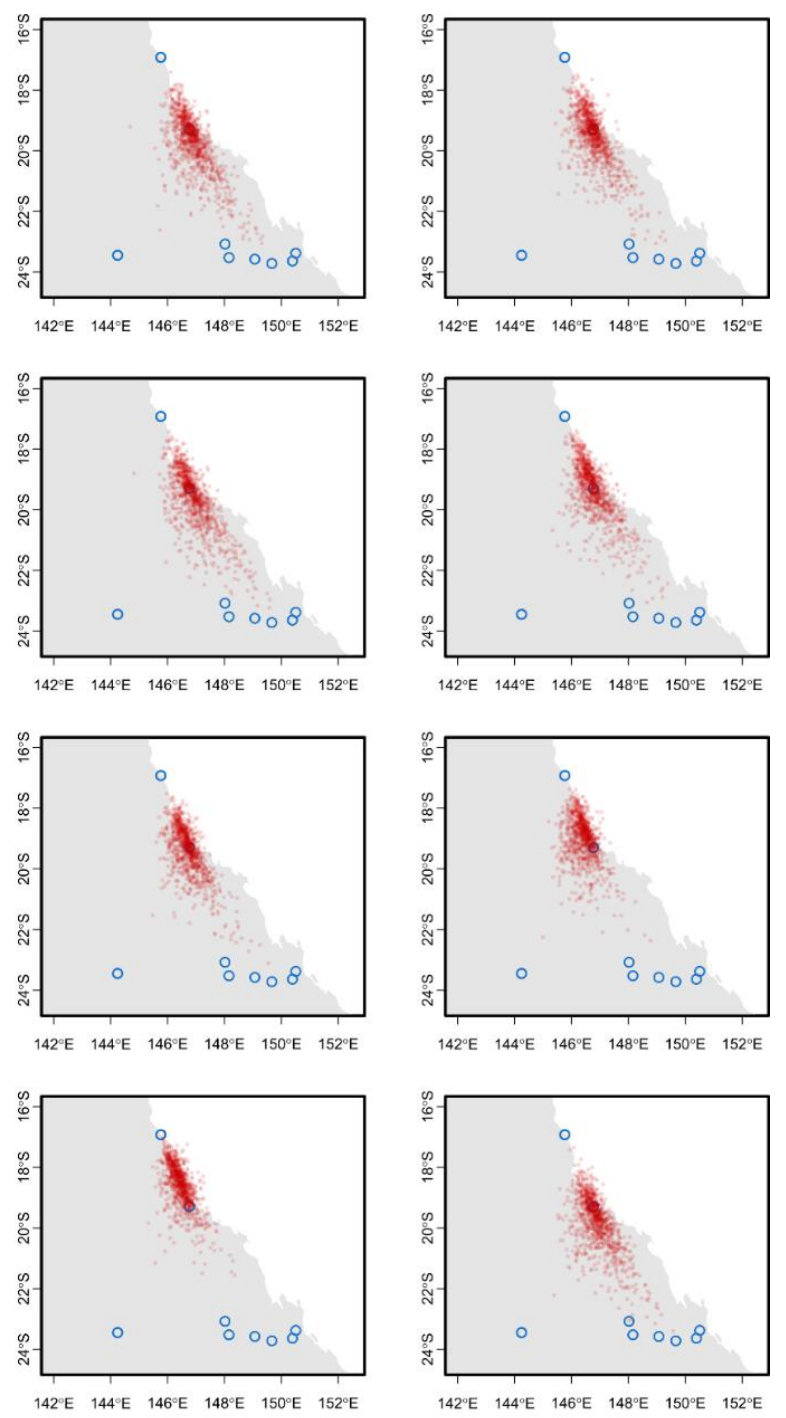

$142^{\circ} \mathrm{E} \quad 144^{\circ} \mathrm{E} \quad 146^{\circ} \mathrm{E} \quad 148^{\circ} \mathrm{E} \quad 150^{\circ} \mathrm{E} \quad 152^{\circ} \mathrm{E}$

Predicted Locations

Figure 2. Origins of the 16 Tennant Creek individuals inferred from genome-wide genetic variation. Blue circles indicate reference sample locations, red circles show inferred origins from 1000 bootstrap replicate runs of Locator. Figs S3-5 show results of similar analyses using the whole dataset (S3) or different subsets of the dataset (S4-5) 
Table 1. Pairwise $F_{\text {ST }}$ of mtDNA variation among Tennant Creek, Cairns, and Townsville populations. Wol+ indicates Wolbachiainfected samples while Wol- are uninfected.

\begin{tabular}{lrrr} 
FST & Townsville (Wol-) & Cairns (Wol-) & Cairns (Wol+) \\
\hline Tennant Creek & 0.26 & 0.85 & 0.85 \\
Townsville (Wol-) & & 0.87 & 0.87 \\
Cairns (Wol-) & & & 0.02
\end{tabular}
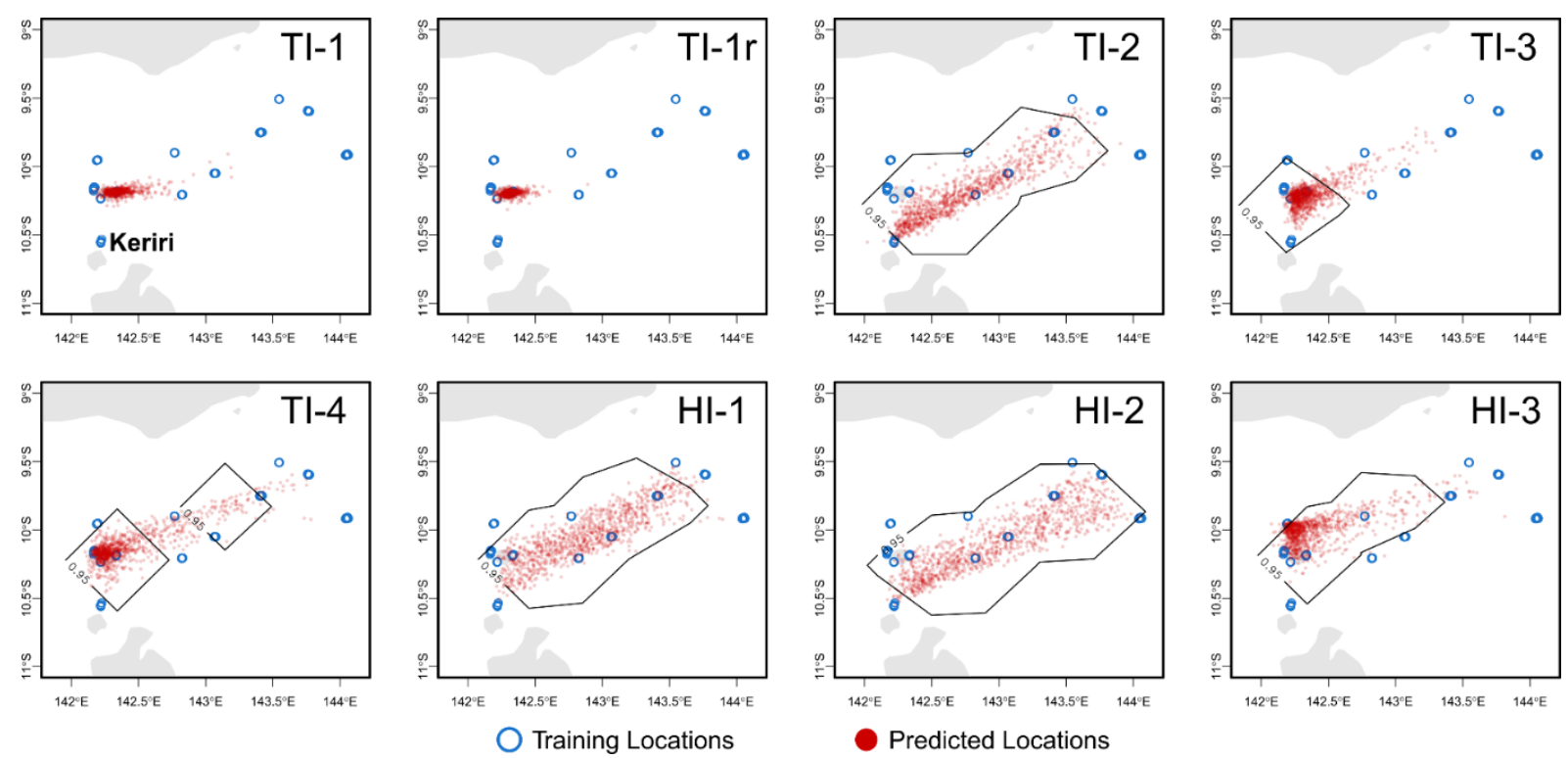

Figure 3. Origins of the $\mathbf{7}$ Torres Strait Islands individuals inferred from genome-wide genetic variation. Samples were detected on Thursday Island (TI) or Horn Island ( $\mathrm{HI})$, and a technical replicate was made of the TI-1 sample. Blue circles indicate reference sample locations, red circles show inferred origins from 1000 bootstrap replicate runs of Locator. Black polygons indicate $95 \%$ confidence intervals of inferences.

\section{Genetic relatedness and inbreeding in the incursions}

Fig 4 displays pairwise Loiselle's $k$ scores for the Torres Strait Island (4a) and Tennant Creek (4b) dyads in rank order, and Wright's inbreeding coefficient $(F)$ scores in the subsampled and refiltered datasets (10601 SNPs for Ae. albopictus (4c); 5073 SNPs for Ae. aegypti (4d)). 

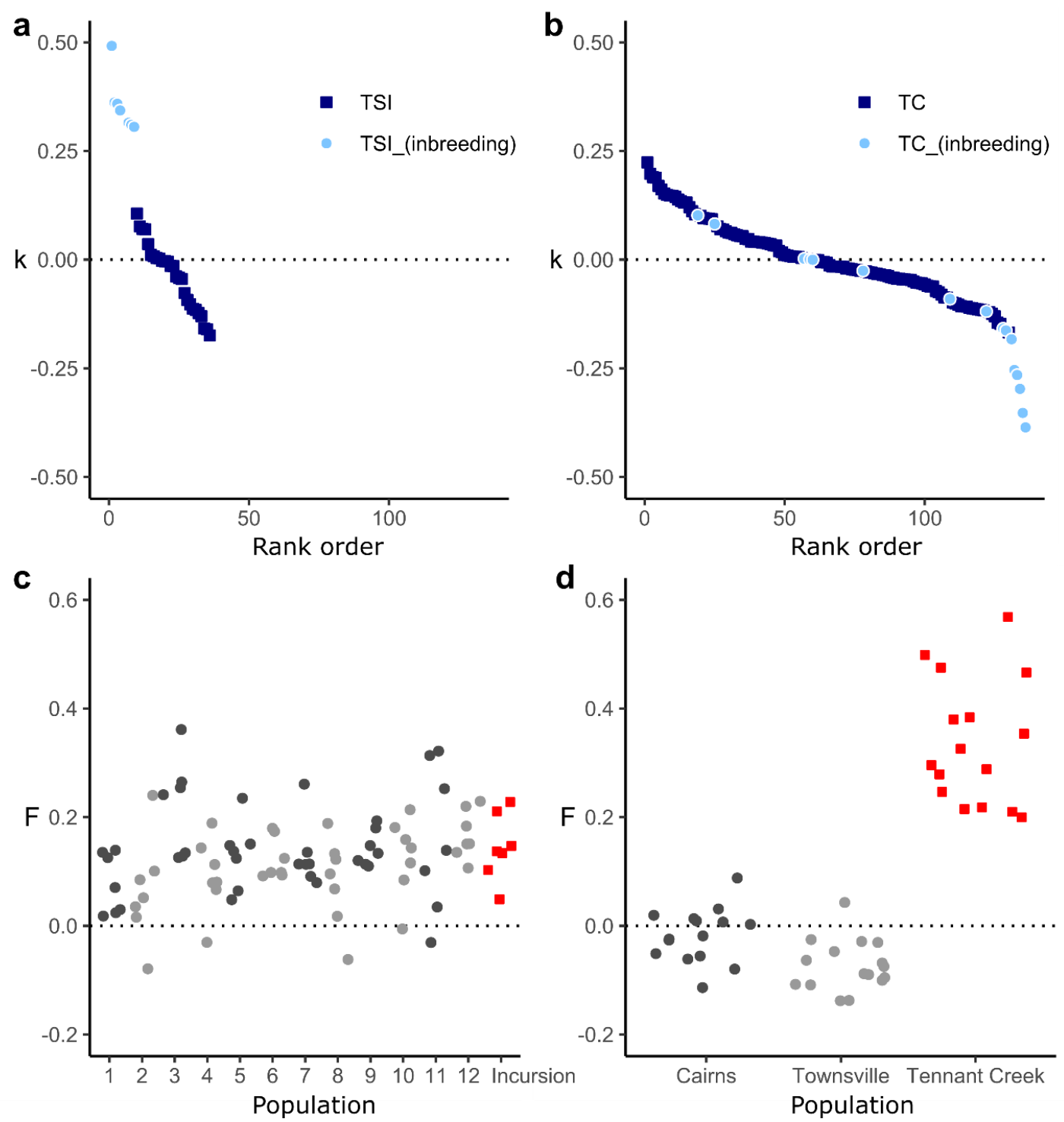

Figure 4. Genetic relatedness $(k)$ and Wright's inbreeding coefficients $(F)$ for Ae. albopictus $(\mathbf{a}, \mathbf{c})$ and Ae. aegypti $(\mathbf{b}, \mathbf{d}) . \mathrm{k}$ scores are of dyads in the Torres Strait Islands (TSI, a) and Tennant Creek (TC, b), where dark blue squares show correlations between alleles in the chromosomes of two different individuals and light blue circles show correlations within the same individual. F scores are of Ae. albopictus (c) and Ae. aegypti (d), where red squares indicate invasive individuals, grey circles indicate other individuals.

Loiselle's $k$ scores represent either correlations between alleles in the chromosomes of two different individuals (dark blue squares) or the same individual (light blue circles; "inbreeding"). The relative magnitudes of inbreeding and non-inbreeding $k$ scores were different in the two datasets. In the Torres Strait Islands, inbreeding $k$ scores were all much higher than the $k$ scores between dyads (Fig 4a). This pattern means that the two chromosomes within each individual are more genetically similar to each other than to 
chromosomes found in other individuals. The large gap between the inbreeding and dyad scores suggests that none of the Torres Strait Island dyads are likely to be from the same family, as dyads from the same family would have chromosomes with high genetic similarity via identity by descent. Instead, these results are evidence that the seven Torres Strait Island incursives each represent distinct incursions. This pattern was not observed at Tennant Creek, where inbreeding $k$ scores were mostly undifferentiated from and in many cases lower than $k$ scores between dyads (Fig $4 b$ ). Chromosomes within individuals are thus no more genetically similar than they are to chromosomes in other individuals. This suggests that the 16 Tennant Creek individuals are all likely to be from the same exact geographical location and are potentially all from the same family.

The above inferences were further supported by variation in $F$ scores. In the Torres Strait Islands, $F$ scores in incursive individuals (Fig $4 \mathrm{c}$, red squares) were of similar magnitude to reference individuals, suggesting no inbreeding in incursions. In Tennant Creek, $F$ scores indicated much higher inbreeding in Tennant Creek relative to Cairns and Townsville reference individuals, suggesting that the Tennant Creek invasion was sourced from a single family (Fig 4d).

\section{Discussion}

Pest genomic databanks provide an increasingly popular means of investigating invasions and incursions (9-16). The value provided by genomic databanks should continue to rise as costs of generating genome-scale data from large numbers of pests continue to decrease and as new genomic methods appropriate for pests are developed (44). This study has used genomic databanks to investigate new threats to biosecurity from Australian incursions of the mosquitoes Ae. aegypti and Ae. albopictus. We were able to infer that the Ae. aegypti invasion of Tennant Creek, Northern Territory came from a location near or within Townsville, Queensland that did not have a Wolbachia infection at fixation. We also traced one of the seven Ae. albopictus incursions into the southern Torres Strait Islands to a specific island and three others to a specific island group (Maluilgal), while none of these incursions were from a nearby island (Keriri) that had previously been identified as an incursion source. Our estimates of genetic relatedness and inbreeding showed that the Tennant Creek invasion was likely sourced from one specific location and possibly from a single family, whereas the Torres Strait incursions were all genetically distinct.

As well as helping solve these specific biosecurity issues, this study helps clarify some ideas around the use of genomic databanks in ongoing pest management. In order for databanks to provide value for money, they should be reusable for tracing over years or decades. However, effects of genetic drift and dispersal will ensure that reference samples in the 
databank will become incrementally less representative of the current populations with each passing generation. Our analysis of Ae. aegypti showed that the 2021 Tennant Creek invasion samples could be traced to the Townsville genetic background represented by samples collected in January 2014. Assuming 10 generations/year for Ae. aegypti, the Tennant Creek and Townsville samples should be separated by $\sim 70$ generations of evolution, plus several generations of strong genetic drift between invasion and detection. The databank of Torres Strait Ae. albopictus showed similar robustness in tracing, wherein incursions sampled 3 years ( $\sim 30$ generations) after the reference samples could in one case be traced to a specific island with very high confidence (TI-1 and TI-1r, Fig 3). This is particularly noteworthy given the much finer spatial scale of the Torres Strait invasion and the low genetic differentiation among islands $\left(\mathrm{F}_{\mathrm{ST}} \approx 0.03(14)\right)$.

Using targeted assays for Wolbachia infection and pyrethroid resistance, combined with mtDNA data from the databank, we were able to trace the Tennant Creek Ae. aegypti with greater specificity than using nuclear genomic data alone. Importantly, these findings indicate that the invasion may have been sourced from an unsampled location near to Townsville, or from a region of outer Townsville where the wMel infection is uncommon. These assays also indicate that the invasion may pose a greater biosecurity threat than otherwise, as without the wMel infection, the Tennant Creek Ae. aegypti should be able to transmit dengue without the transmission blocking effects of $w$ Mel (45).

The different patterns of genetic relatedness observed at Tennant Creek and the Torres Strait provide a useful indication of the genetic characteristics of each invasive system, in that we can infer the incursions into the southern Torres Strait Islands are independent from each other, whereas the invasion of Tennant Creek is from a single source. These genetic inferences align with detection locations, where the Tennant Creek samples were collected within $\sim 80 \mathrm{~m}$ of each other while the Horn and Thursday Island incursions were spread across $600 \mathrm{~m}-1 \mathrm{~km}$. Understanding the independence of incursions can be useful for building predictive models of pest incursion risk as it can indicate propagule pressure (46), though these estimates will reflect effective rather than census population sizes of incursions. The findings at Tennant Creek indicate that greater caution will be required for studies seeking to investigate new invasions using close kin dyad methodologies $(47,48)$. While close kin dyad methods have shown promise for investigating invasions of 100 generations age (14), close kin methods should be applied cautiously to invasions that are very new or that are sourced from a small genetic pool.

\section{Acknowledgements}

We would like to thank all Medical Entomology staff who were involved in mosquito surveillance and identification. We thank Nigel Beebe and Queensland Health for sample 
collection. Funding was provided by Queensland Health and the Menzies School of Health Research as well as the National Health and Medical Research Council (grant numbers 1132412, 1118640).

\section{References}

1. Diagne C, Leroy B, Vaissière A-C, Gozlan RE, Roiz D, Jarić I, et al. High and rising economic costs of biological invasions worldwide. Nature. 2021 Apr;592(7855):571-6.

2. Sardain A, Sardain E, Leung B. Global forecasts of shipping traffic and biological invasions to 2050. Nat Sustain. 2019 Apr;2(4):274-82.

3. Gao Y-F, Gong Y-J, Cao L-J, Chen J-C, Gao Y-L, Mirab-balou M, et al. Geographical and interspecific variation in susceptibility of three common thrips species to the insecticide, spinetoram. J Pest Sci. 2021 Jan 1;94(1):93-9.

4. Muzari MO, Devine G, Davis J, Crunkhorn B, van den Hurk A, Whelan P, et al. Holding back the tiger: Successful control program protects Australia from Aedes albopictus expansion. Apperson C, editor. PLOS NTDS. 2017 Feb;11(2):e0005286.

5. Caley P, Ingram R, De Barro P. Entry of exotic insects into Australia: Does border interception count match incursion risk? Biol Invasions. 2015 Apr;17(4):1087-94.

6. Robinson A, Burgman MA, Cannon R. Allocating surveillance resources to reduce ecological invasions: maximizing detections and information about the threat. Ecol Appl. 2011 Jun;21(4):1410-7.

7. Mehta SV, Haight RG, Homans FR, Polasky S, Venette RC. Optimal detection and control strategies for invasive species management. Ecol Econ. 2007 Mar;61(2-3):23745.

8. Myers JH, Simberloff D, Kuris AM, Carey JR. Eradication revisited: dealing with exotic species. TREE. 2000 Aug;15(8):316-20.

9. Chen MZ, Cao L, Li BY, Chen JC, Gong YJ, Yang Q, et al. Migration trajectories of the diamondback moth Plutella xylostella in China inferred from population genomic variation. Pest Manag Sci. 2021;77(4):ps.6188-ps.6188.

10. Gloria-Soria A, Lima A, Lovin DD, Cunningham JM, Severson DW, Powell JR. Origin of a High-Latitude Population of Aedes aegypti in Washington, DC. AJTMH. 2018 Feb;98(2):445-52.

11. Kelly ET, Mack LK, Campos M, Grippin C, Chen T-Y, Romero-Weaver AL, et al. Evidence of Local Extinction and Reintroduction of Aedes aegypti in Exeter, California. Front Trop Dis [Internet]. 2021 [cited 2022 Jan 19];2. Available from: https://www.frontiersin.org/article/10.3389/fitd.2021.703873 
12. Popa-Báez Á-D, Lee SF, Yeap HL, Westmore G, Crisp P, Li D, et al. Tracing the origins of recent Queensland fruit fly incursions into South Australia, Tasmania and New Zealand. Biol Invasions. 2021 Apr 1;23(4):1117-30.

13. Schmidt TL, Chung J, van Rooyen AR, Sly A, Weeks AR, Hoffmann AA. Incursion pathways of the Asian tiger mosquito (Aedes albopictus) into Australia contrast sharply with those of the yellow fever mosquito (Aedes aegypti). Pest Manag Sci. 2020 Jul;76(12):4202-9.

14. Schmidt TL, Swan T, Chung J, Karl S, Demok S, Yang Q, et al. Spatial population genomics of a recent mosquito invasion. Mol Ecol. 2021 Dec;30(5):1174-89.

15. Schmidt TL, van Rooyen AR, Chung J, Endersby-Harshman NM, Griffin PC, Sly A, et al. Tracking genetic invasions: Genome-wide single nucleotide polymorphisms reveal the source of pyrethroid-resistant Aedes aegypti (yellow fever mosquito) incursions at international ports. Evol Appl. 2019 Mar;12(6):1136-46.

16. Sherpa S, Blum MGB, Capblancq T, Cumer T, Rioux D, Després L. Unravelling the invasion history of the Asian tiger mosquito in Europe. Mol Ecol. 2019 Apr;28(9):236077.

17. O'Neill SL, Ryan PA, Turley AP, Wilson G, Retzki K, Iturbe-Ormaetxe I, et al. Scaled deployment of Wolbachia to protect the community from dengue and other Aedes transmitted arboviruses. Gates Open Res. 2018 Nov;2:36-36.

18. Ryan PA, Turley AP, Wilson G, Hurst TP, Retzki K, Brown-Kenyon J, et al. Establishment of wMel Wolbachia in Aedes aegypti mosquitoes and reduction of local dengue transmission in Cairns and surrounding locations in northern Queensland, Australia. Gates Open Res. 2020 Apr;3:1547.

19. Schmidt TL, Barton NH, Rašić G, Turley AP, Montgomery BL, Iturbe-Ormaetxe I, et al. Local introduction and heterogeneous spatial spread of dengue-suppressing Wolbachia through an urban population of Aedes aegypti. Read A, editor. PLOS Biology. 2017 May;15(5):e2001894.

20. Maynard AJ, Ambrose L, Cooper RD, Chow WK, Davis JB, Muzari MO, et al. Tiger on the prowl: Invasion history and spatio-temporal genetic structure of the Asian tiger mosquito Aedes albopictus (Skuse 1894) in the Indo-Pacific. Vasilakis N, editor. PLOS NTDS. 2017 Apr;11(4):e0005546-e0005546.

21. Schmidt TL, Filipović I, Hoffmann AA, Rašić G. Fine-scale landscape genomics helps explain the slow spatial spread of Wolbachia through the Aedes aegypti population in Cairns, Australia. Heredity. 2018 May;120(5):386-95.

22. Rašić G, Filipović I, Callahan AG, Stanford D, Chan A, Lam-Phua SG, et al. The queenslandensis and the type Form of the Dengue Fever Mosquito (Aedes aegypti L.) Are Genomically Indistinguishable. PLOS NTDS. 2016 Nov;10(11):e0005096. 
23. Peterson BK, Weber JN, Kay EH, Fisher HS, Hoekstra HE. Double Digest RADseq: An Inexpensive Method for De Novo SNP Discovery and Genotyping in Model and NonModel Species. Orlando L, editor. PLoS ONE. 2012 May;7(5):e37135-e37135.

24. Rašić G, Filipović I, Weeks AR, Hoffmann AA. Genome-wide SNPs lead to strong signals of geographic structure and relatedness patterns in the major arbovirus vector, Aedes aegypti. BMC Genom. 2014 Apr;15(1):1-12.

25. Rochette NC, Rivera-Colón AG, Catchen JM. Stacks 2: Analytical methods for pairedend sequencing improve RADseq-based population genomics. Mol Ecol. 2019 Nov;28(21):4737-54.

26. Matthews BJ, Dudchenko O, Kingan SB, Koren S, Antoshechkin I, Crawford JE, et al. Improved reference genome of Aedes aegypti informs arbovirus vector control. Nature. 2018 Nov;563(7732):501-7.

27. Boyle JH, Rastas PMA, Huang X, Garner AG, Vythilingam I, Armbruster PA. A LinkageBased Genome Assembly for the Mosquito Aedes albopictus and Identification of Chromosomal Regions Affecting Diapause. Insects. 2021 Feb;12(2):167.

28. Langmead B, Salzberg SL. Fast gapped-read alignment with Bowtie 2. Nat Methods. 2012;9(4):357-9.

29. Danecek P, Auton A, Abecasis G, Albers CA, Banks E, DePristo MA, et al. The variant call format and VCFtools. Bioinformatics. 2011 Aug;27(15):2156-8.

30. Linck E, Battey CJ. Minor allele frequency thresholds strongly affect population structure inference with genomic data sets. Mol Ecol Res. 2019 Jan;19(3):639-47.

31. Battey CJ, Ralph PL, Kern AD. Predicting geographic location from genetic variation with deep neural networks. elife. 2020 Jun;9:1-22.

32. Lee SF, White VL, Weeks AR, Hoffmann AA, Endersby NM. High-throughput PCR assays to monitor Wolbachia infection in the dengue mosquito (Aedes aegypti) and Drosophila simulans. Appl Environ Microbiol. 2012 Jul;78(13):4740-3.

33. Ross PA, Wiwatanaratanabutr I, Axford JK, White VL, Endersby-Harshman NM, Hoffmann AA. Wolbachia Infections in Aedes aegypti Differ Markedly in Their Response to Cyclical Heat Stress. PLoS Pathog. 2017 Jan 5;13(1):e1006006.

34. Hoffmann A, Turelli M. Cytoplasmic incompatibility in insects. In: SL O, AA H, JH W, editors. Influential passengers: inherited microorganisms and arthropod reproduction. Oxford: Oxford University Press; 1997. p. 42-80.

35. Yeap HL, Rašić G, Endersby-Harshman NM, Lee SF, Arguni E, Le Nguyen H, et al. Mitochondrial DNA variants help monitor the dynamics of Wolbachia invasion into host populations. Heredity. 2016 Mar;116(3):265-76. 
36. Behura SK, Lobo NF, Haas B, DeBruyn B, Lovin DD, Shumway MF, et al. Complete sequences of mitochondria genomes of Aedes aegypti and Culex quinquefasciatus and comparative analysis of mitochondrial DNA fragments inserted in the nuclear genomes. Insect Biochem Mol. 2011 Oct;41(10):770-7.

37. Hlaing $T$, Tun-Lin $W$, Somboon $P$, Socheat $D$, Setha $T$, Min S, et al. Mitochondrial pseudogenes in the nuclear genome of Aedes aegypti mosquitoes: Implications for past and future population genetic studies. BMC Genet. 2009 Mar;10(1):11-11.

38. Endersby-Harshman NM, Schmidt TL, Chung J, van Rooyen A, Weeks AR, Hoffmann AA. Heterogeneous genetic invasions of three insecticide resistance mutations in IndoPacific populations of Aedes aegypti (L.). Mol Ecol. 2020 Apr;29(9):1628-41.

39. Endersby-Harshman NM, Wuliandari JR, Harshman LG, Frohn V, Johnson BJ, Ritchie SA, et al. Pyrethroid Susceptibility Has Been Maintained in the Dengue Vector, Aedes aegypti (Diptera: Culicidae), in Queensland, Australia. J Med Entomol. 2017 Nov;54(6):1649-58.

40. Loiselle BA, Sork VL, Nason J, Graham C. Spatial genetic structure of a tropical understory shrub, Psychotria officinalis (Rubiaceae). Am J Bot. 1995 Nov;82(11):14205.

41. Hardy OJ, Vekemans X. SPAGeDi: a versatile computer program to analyse spatial genetic structure at the individual or population levels. Mol Ecol Notes. 2002 Dec;2(4):618-20.

42. Vekemans $X$, Hardy OJ. New insights from fine-scale spatial genetic structure analyses in plant populations. Mol Ecol. 2004;13(4):921-35.

43. Schmidt TL, Jasper M-E, Weeks AR, Hoffmann AA. Unbiased population heterozygosity estimates from genome-wide sequence data. Meth Ecol Evol. 2021;12(10):1888-98.

44. North HL, McGaughran A, Jiggins CD. Insights into invasive species from whole-genome resequencing. Mol Ecol. 2021;30(23):6289-308.

45. Walker T, Johnson PH, Moreira LA, Iturbe-Ormaetxe I, Frentiu FD, McMeniman CJ, et al. The wMel Wolbachia strain blocks dengue and invades caged Aedes aegypti populations. Nature. 2011 Aug;476(7361):450-3.

46. Camac J, Baumgartner J, Hester S, Subasinghe R, Collins S. Using edmaps \& Zonation to inform multi-pest early-detection surveillance designs. Centre of Excellence for Biosecurity Risk Analysis (CEBRA); 2021 Aug. Available from: https://rune.une.edu.au/web/handle/1959.11/31490

47. Jasper ME, Hoffmann AA, Schmidt TL. Estimating dispersal using close kin dyads: The KINDISPERSE R package. Molecular Ecology Resources. 2021; Available from: https://www.biorxiv.org/content/10.1101/2021.07.28.454079v1 
bioRxiv preprint doi: https://doi.org/10.1101/2022.01.19.477022; this version posted February $14,2022$. The copyright holder for this

preprint (which was not certified by peer review) is the author/funder, who has granted bioRxiv a license to display the preprint in perpetuity. It is made available under aCC-BY 4.0 International license.

48. Waples RS, Feutry P. Close-kin methods to estimate census size and effective population size. Fish and Fisheries. 2021;n/a(n/a). Available from:

https://onlinelibrary.wiley.com/doi/abs/10.1111/faf.12615 
bioRxiv preprint doi: https://doi.org/10.1101/2022.01.19.477022; this version posted February 14, 2022. The copyright holder for this

preprint (which was not certified by peer review) is the author/funder, who has granted bioRxiv a license to display the preprint in perpetuity. It is made available under aCC-BY 4.0 International license.

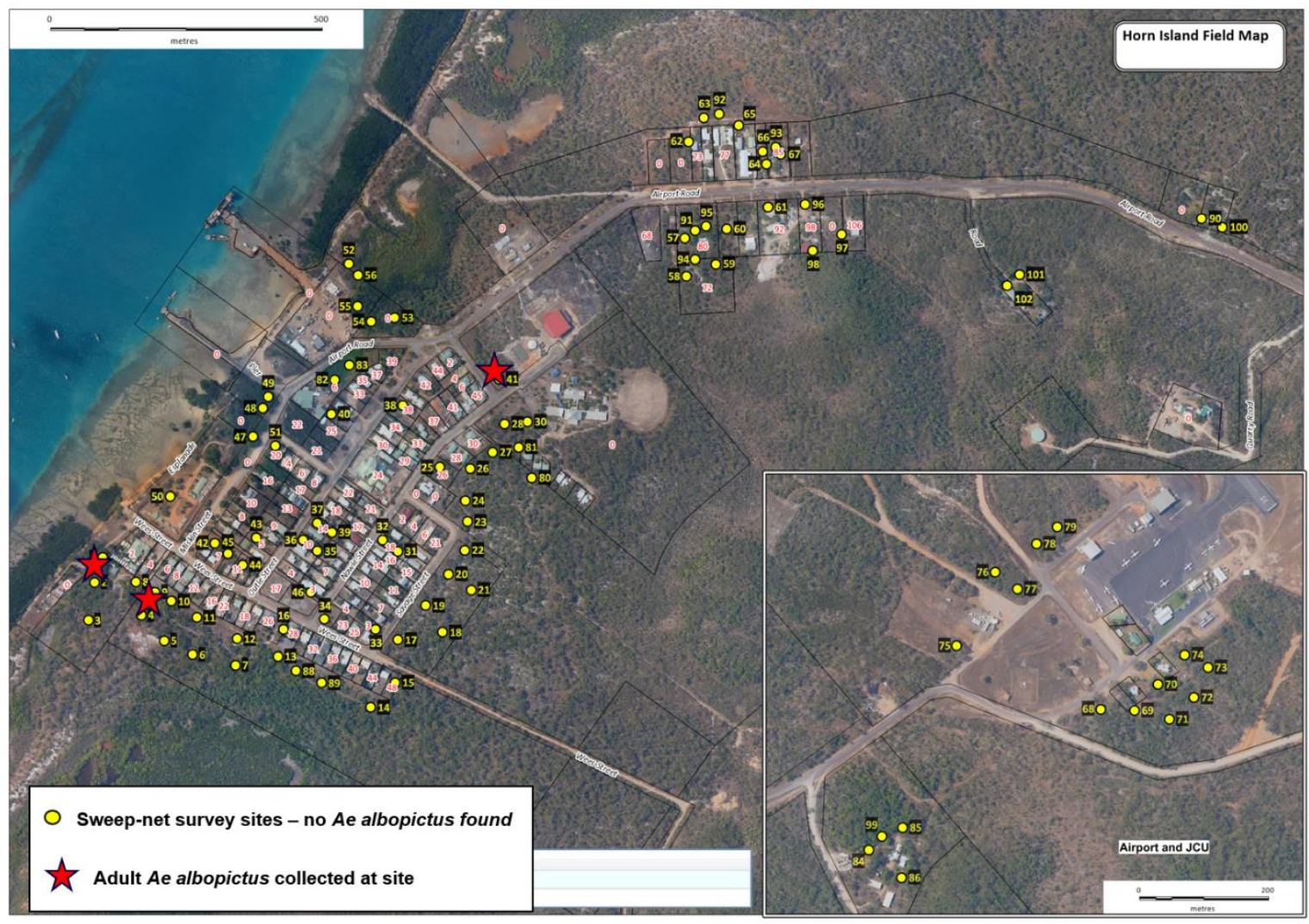

Figure S1: Locations of the three Aedes albopictus collected on Horn Island (red stars). Yellow circles indicate sweep-net survey sites. 
bioRxiv preprint doi: https://doi.org/10.1101/2022.01.19.477022; this version posted February 14, 2022. The copyright holder for this

preprint (which was not certified by peer review) is the author/funder, who has granted bioRxiv a license to display the preprint in perpetuity. It is made available under aCC-BY 4.0 International license.

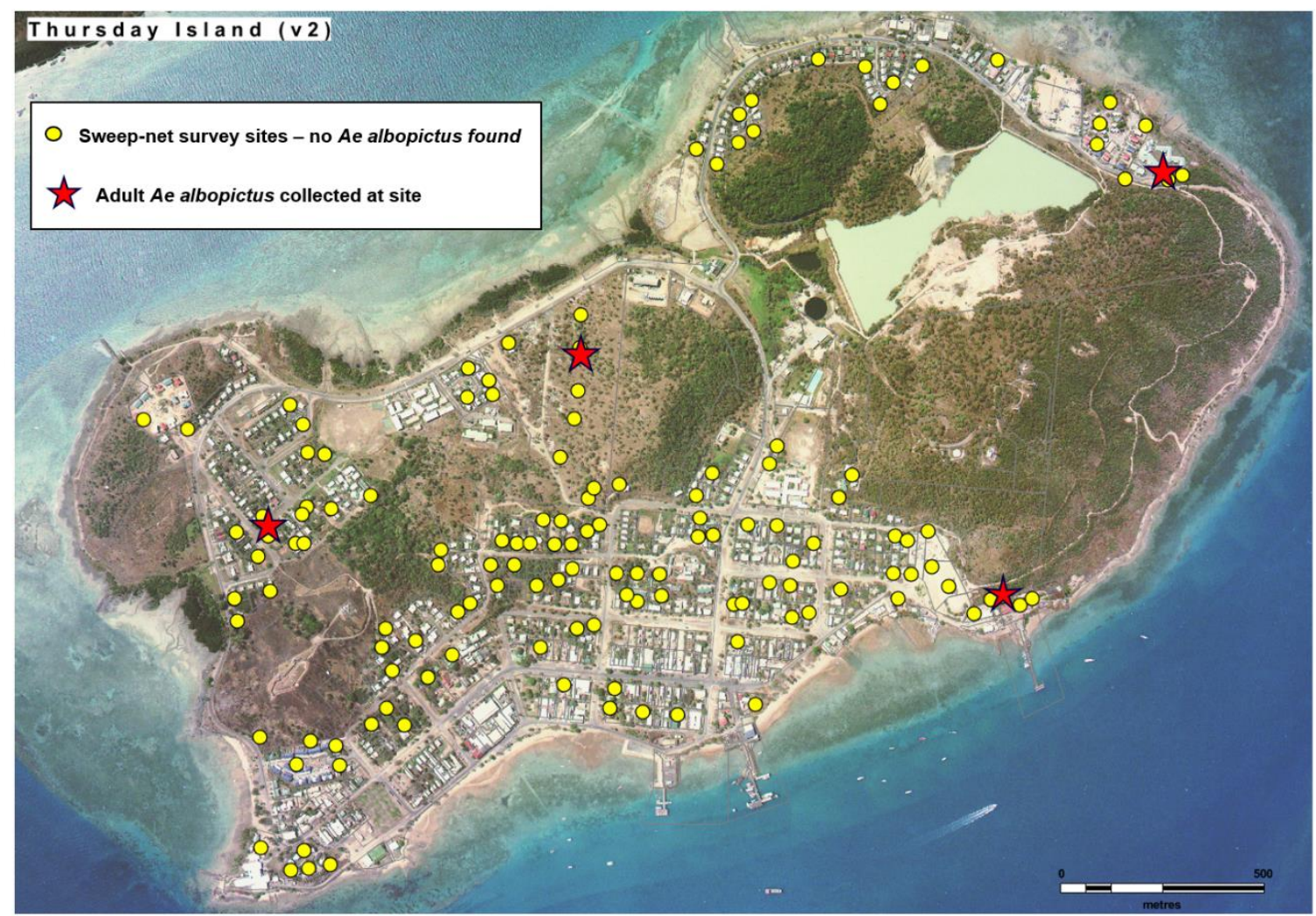

Figure S2: Locations of the four Aedes albopictus collected on Thursday Island (red stars). Yellow circles indicate sweep-net survey sites. 

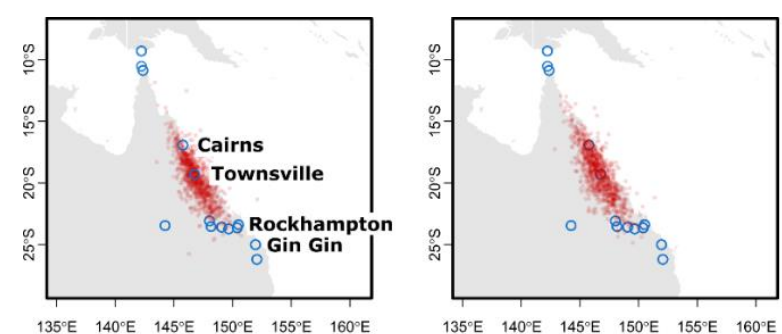

$135^{\circ} \mathrm{E} \quad 140^{\circ} \mathrm{E} \quad 145^{\circ} \mathrm{E} \quad 150^{\circ} \mathrm{E} \quad 155^{\circ} \mathrm{E} \quad 160^{\circ} \mathrm{E}$

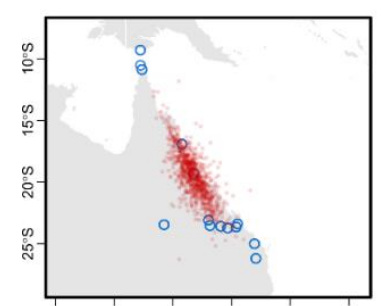

$\begin{array}{llllll}135^{\circ} \mathrm{E} & 140^{\circ} \mathrm{E} & 145^{\circ} \mathrm{E} & 150^{\circ} \mathrm{E} & 155^{\circ} \mathrm{E} & 160^{\circ} \mathrm{E}\end{array}$

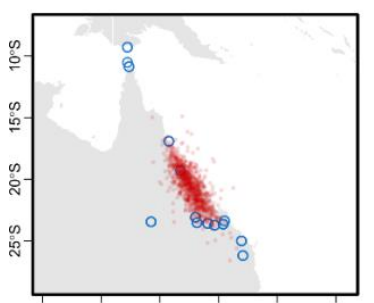

$135^{\circ} \mathrm{E} \quad 140^{\circ} \mathrm{E} \quad 145^{\circ} \mathrm{E} \quad 150^{\circ} \mathrm{E} \quad 155^{\circ} \mathrm{E} \quad 160^{\circ} \mathrm{E}$

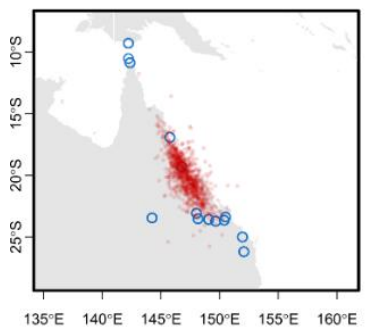

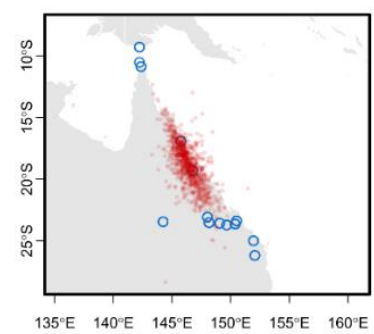

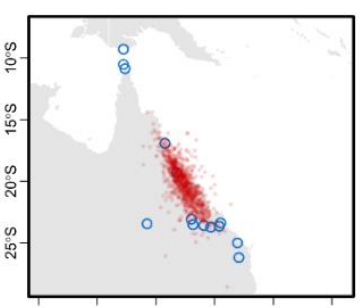

$135^{\circ} \mathrm{E} \quad 140^{\circ} \mathrm{E} \quad 145^{\circ} \mathrm{E} \quad 150^{\circ} \mathrm{E} \quad 155^{\circ} \mathrm{E} \quad 160^{\circ} \mathrm{E}$

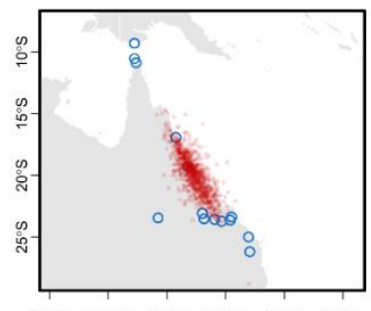

Training Locations
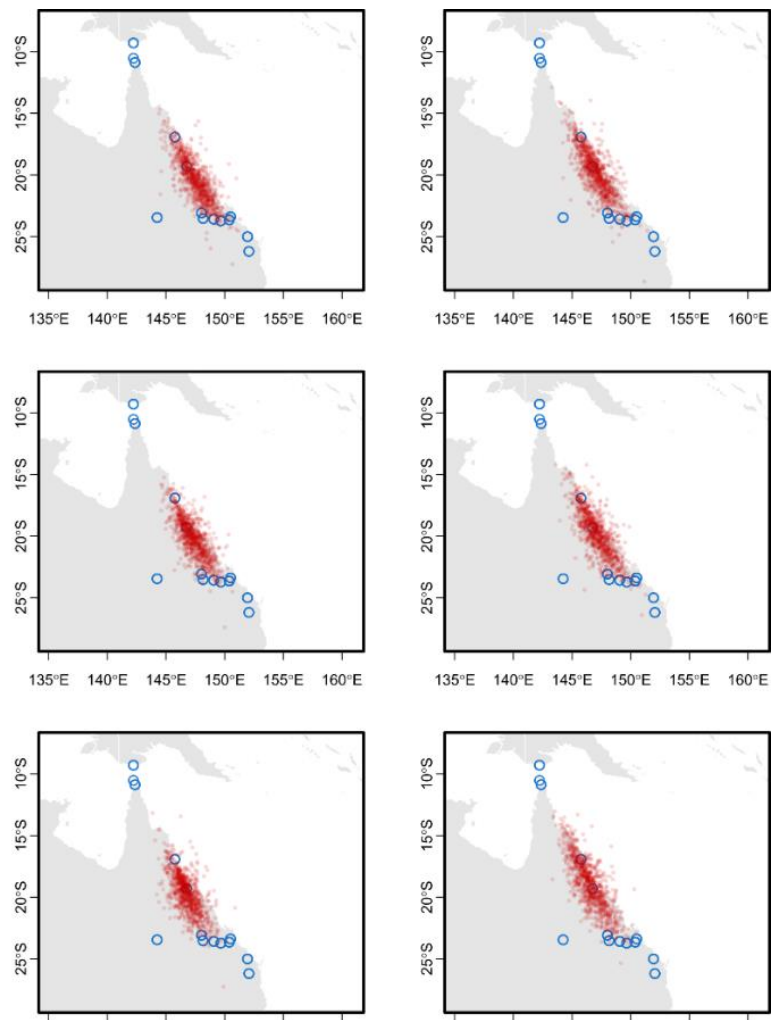

$135^{\circ} \mathrm{E} \quad 140^{\circ} \mathrm{E} \quad 145^{\circ} \mathrm{E} \quad 150^{\circ} \mathrm{E} \quad 155^{\circ} \mathrm{E} \quad 160^{\circ} \mathrm{E}$
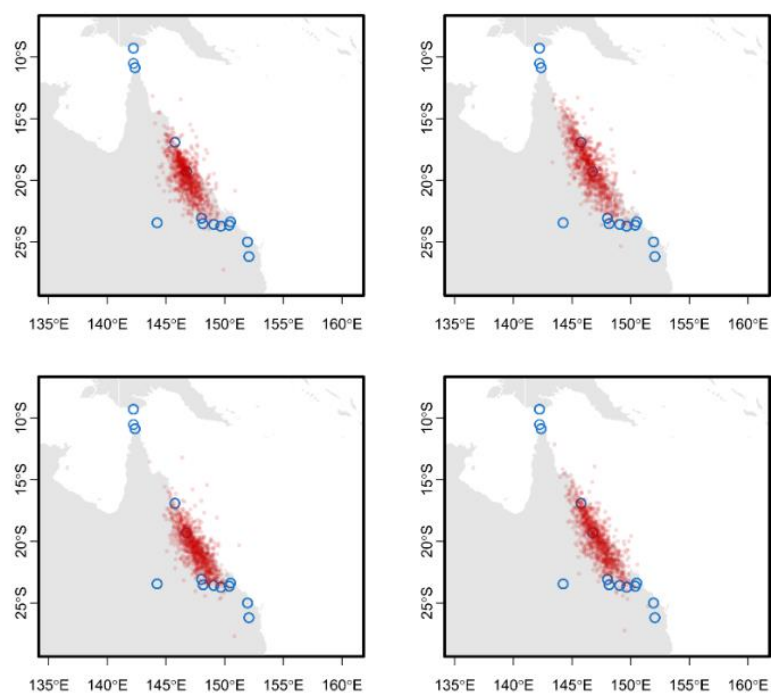

Predicted Locations

Figure S3. Tracing of the $\mathbf{1 6}$ Tennant Creek individuals using the entire genomic databank. Blue circles indicate reference sample locations, red circles show inferred origins from 1000 bootstrap replicate runs of Locator. 

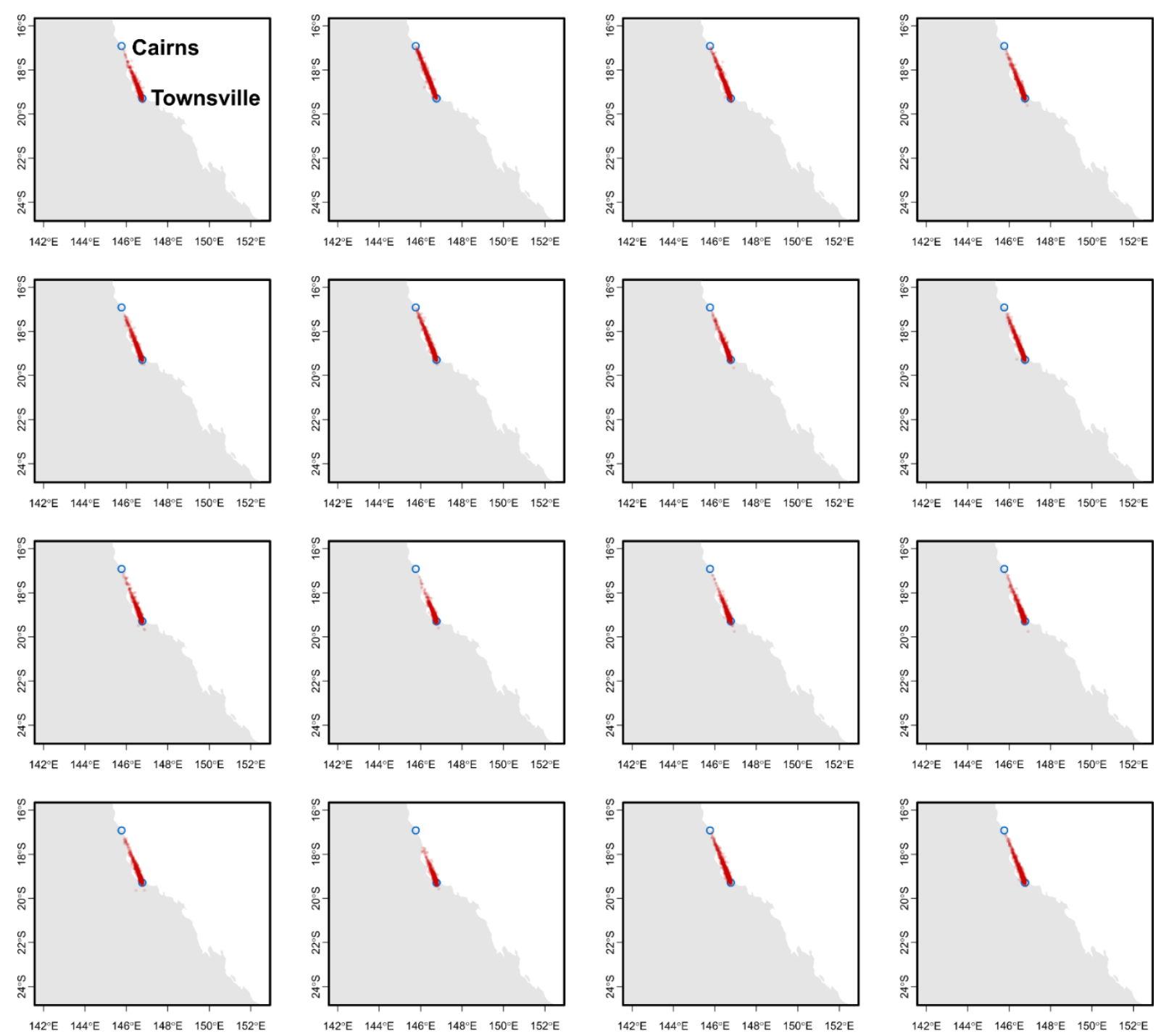

Training Locations

Predicted Locations

Figure S4. Tracing of the 16 Tennant Creek individuals using only Cairns and Townsville. Blue circles indicate reference sample locations, red circles show inferred origins from 1000 bootstrap replicate runs of Locator. 

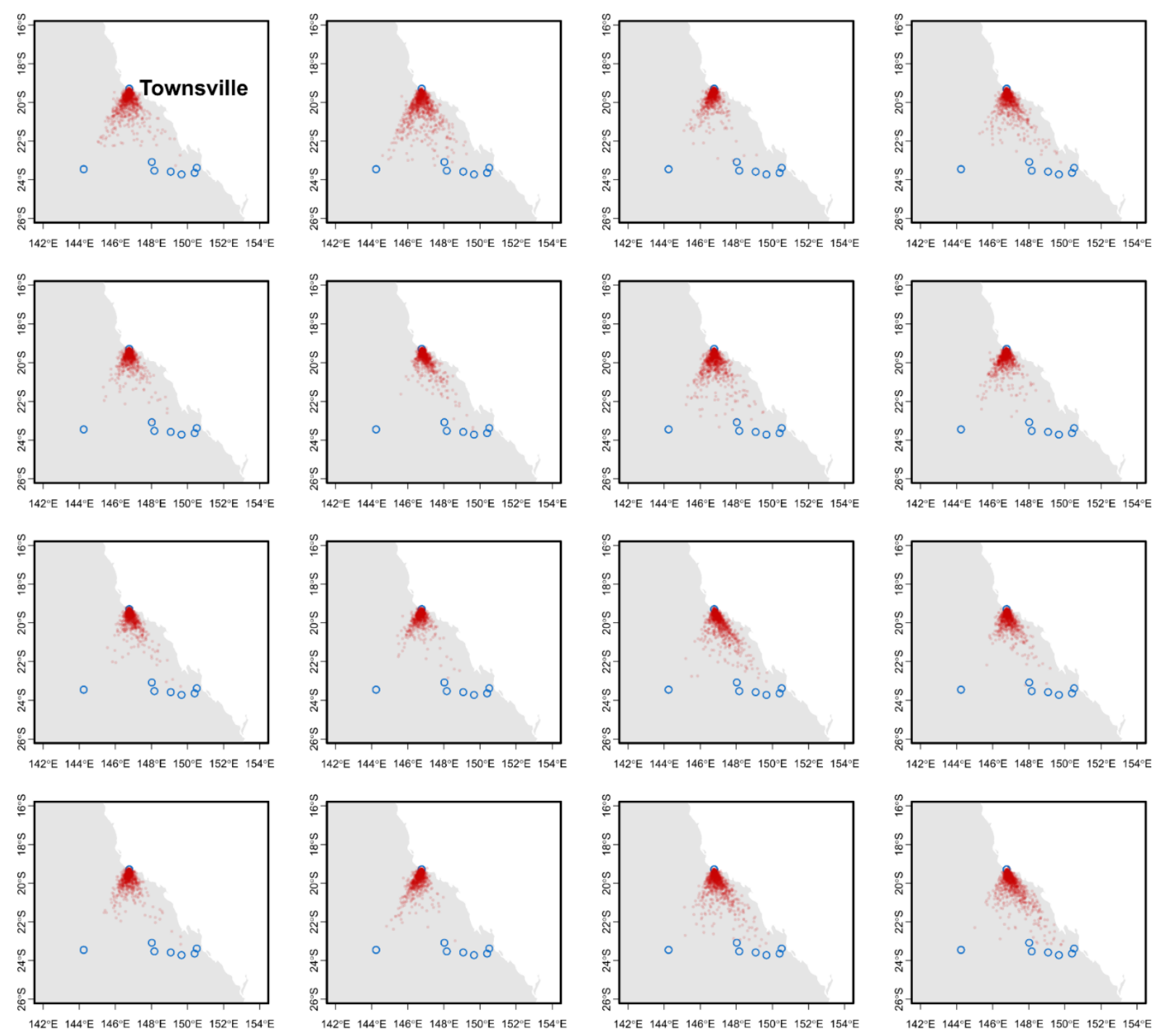

Training Locations

Predicted Locations

Figure S5. Tracing of the 16 Tennant Creek individuals using only Townsville and nearby populations in southern Queensland. Blue circles indicate reference sample locations, red circles show inferred origins from 1000 bootstrap replicate runs of Locator. 